\title{
Consecuencias de la manipulación fotográfica en las agencias de noticias: Associated Press, Reuters, France Press, European Pressphoto Agency y EFE. El caso del fotoperiodismo de guerra
}

\author{
Eva LAVÍN DE LAS HERAS \\ elavin@ucjc.edu \\ Universidad Camilo José Cela \\ Javier CHIVITE FERNÁNDEZ \\ jchivite@ucjc.edu \\ Universidad Camilo José Cela
}

Recibido: 11 de marzo de 2014

Aceptado: 13 de octubre de 2014

\begin{abstract}
Resumen
El fotoperiodismo de guerra ha experimentado una revolución en los últimos años, con la aparición de la fotografía digital y el desarrollo de programas informáticos que permiten la manipulación de la imagen casi en el mismo lugar en el que se ha realizado la captura. Asimismo, las agencias de noticias y los medios de comunicación receptores de esas fotografías se han visto obligados a utilizar herramientas cada vez más complejas para detectar estas adulteraciones que en algunos casos son prácticamente imperceptibles. Como consecuencia de esta realidad y de la mala praxis de algunos fotógrafos, las principales agencias de noticias (Associated Press, Reuters, Reuters, Reuters y EFE) se han visto obligadas a modificar sus normativas internas con el objetivo de garantizar la fidelidad de las imágenes que distribuyen.
\end{abstract}

Palabras clave: fotografía de guerra, fotoperiodismo, manipulación, código ético, agencias de noticias.

\section{Consequences of Photographic Manipulation in the News Agencies: Associated Press, Reuters, France Press, European Pressphoto Agency and EFE: the Case of Photojournalism in War Coverage}

\begin{abstract}
Photojournalism in war coverage has gone through a complete revolution over the last few years due to the appearance of digital photography and the development of computer programmes enabling photo manipulation, almost at the same instant the image has been captured. Because of this, the different news agencies and news media receiving these photos have been forced to use increasingly complex tools to detect these adulterations, in some cases, practically imperceptible. The added factor of some photographers engaging in malpractice has compelled the main news agencies (Associated Press, Reuters, European Pressphoto Agency, France Press y EFE) to modify their regulatory guidelines in order to guarantee the authenticity of the images they issue.
\end{abstract}

Keywords: war photography, photojournalism, manipulation, ethical code, news agencies.

\section{Referencia normalizada}

LAVÍN DE LAS HERAS, Eva y CHIVITE FERNÁNDEZ, Javier (2015): “Consecuencias de la manipulación fotográfica en las agencias de noticias: Associated Press, Reuters, France Press, European Pressphoto Agency y EFE. El caso del fotoperiodismo de guerra". Estudios sobre el Mensaje Periodístico. Vol. 21, Núm. 1 (enero-junio), págs.: 333-351. Madrid, Servicio de Publicaciones de la Universidad Complutense.

Sumario: 1. Introducción. 2. Fuentes y metodología. 3. Desarrollo; 3.1.Guerra de Crimea; 3.2. Guerra de Secesión; 3.3. Primer Guerra Mundial; 3.4. Segunda Guerra Mundial. 4. Aparición de la fotografía digital; 4.1. Brian Walski (2003); 4.2. Adnan Hajj (2007); 4.3. France Press (2008). 5. Análisis de los ma- 
nuales de estilo; 5.1. Reuters; 5.2. EFE; 5.3. Associated Press; 5.4. France Press; 5.5. European Pressphoto Agency. 6. Incongruencia informativa. 7. Conclusiones. 8. Referencias bibliográficas.

\section{Introducción}

El 29 de septiembre de 2013, el fotógrafo mexicano Narciso Contreras captó una imagen mientras se encontraba asistiendo a un intercambio de disparos entre las fuerzas de la oposición siria y el gobierno de Bachar Al Assad, en la aldea de Telata. En un momento determinado, observó cómo un miliciano, ataviado con un pañuelo palestino en la cabeza y una túnica de color claro, cogía con la mano izquierda su AK-47 U, lo colocaba en primer plano, trazando una diagonal casi perfecta y procedía a levantarse añadiendo a la fotografía movimiento y acción. Contreras disparó. Posteriormente, cuando analizó la imagen en su ordenador, comprobó que en la esquina inferior izquierda aparecía la cámara de vídeo de un compañero. Esa cámara podía distraer al espectador de la intensidad dramática de la instantánea. Por eso, Contreras, ganador del premio Pulitzer 2013 por su cobertura en Siria, decidió eliminarla mediante un programa informático y enviar la imagen a sus editores de Associated Press. Estos descubrieron la manipulación y, como consecuencia, el fotoperiodista de guerra fue despedido.

Contreras reconoció a sus editores que había manipulado la foto y que utilizó un software para eliminar la cámara porque podía distraer a quienes miraran la imagen. "Tomé la decisión equivocada. Me siento avergonzado por eso. Pueden ir a mis archivos y verán que esto es un caso que ocurrió, probablemente, en un momento de mucho estrés, en una situación muy difícil. Pero sí, me pasó a mí y tengo que asumir las consecuencias" (AP, 2014).
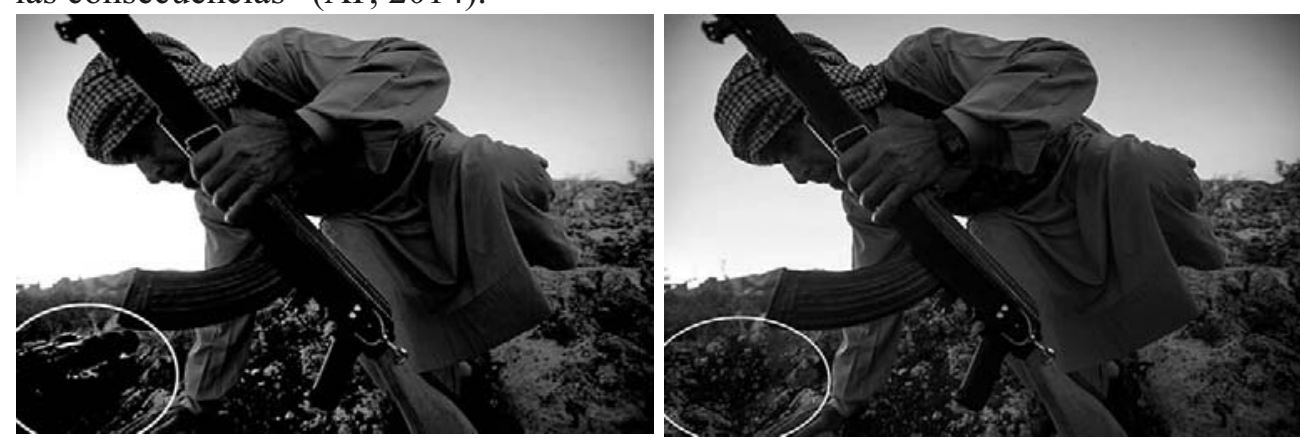

Ilustración 1: Fotografía original (izquierda) y manipulada (derecha) de Narciso Contreras.

No es el único caso de manipulación informativa en el que un fotoperiodista ha acabado siendo despedido. La tecnología que tienen a su disposición los profesionales de la imagen y el nivel de exigencia al que están sometidos, hace que algunos de ellos recurran a modificar la foto, a adulterarla, a manipularla. Por eso, los medios de comunicación en general, y las agencias de noticias en particular, han cambiado sus normativas internas para que la imagen apenas se retoque, básicamente limitándolo a los mismos procesos que antes se hacían en el cuarto oscuro.

Cuando en 1839 apareció la fotografía, al principio dirigió su mirada hacia la pintura, había un interés por construir de manera creativa, original, testimonial incluso, una realidad que era fotografiada para que pasara a la posteridad, con una intencio- 
nalidad estética en la mayoría de los casos (Formiguera, 2006). También se generó un debate sobre la intencionalidad de la imagen fotográfica. Unos opinaban que debía ser simplemente un apéndice más de las Bellas Artes (como la pintura o la escultura) y que debía limitarse a dar testimonio de una realidad. Otros, sin embargo, ya adivinaban, como nos dice Albarrán (2010) las posibilidades que podía alcanzar, un estatus artístico acudiendo a la escenificación como medio para crear imágenes.

Susan Sontag (2004) afirma que, al final, fotografiar es encuadrar, y encuadrar es excluir. Algo que también sostiene Caballo Ardila (2005), que considera que la imagen pasa por una serie de filtros cargados de subjetividad: desde el fotógrafo que mira a través del visor de su cámara, hasta llegar a su publicación, donde adquiere un objetivo concreto, que conllevará una nueva carga de intencionalidad que no tiene por qué coincidir con el sentido que tenía en su origen.

A pesar de este componente subjetivo, Sontag (2004) asegura que las fotografías menos pulidas son recibidas por el público como si estuvieran dotadas de una especial autenticidad. También Caminos et al. (2008), apoyan este argumento, apuntando que para muchos autores y para el público en general, es el "espejo de la realidad", una prueba irrefutable y objetiva, a pesar de sus evidentes manipulaciones formales.

Como veremos en este artículo, la fotografía digital se ha convertido en una herramienta fundamental en el trabajo de los fotoperiodistas de guerra. Todos los autores coinciden en una idea: "La facilidad de la fotografía digital, no sólo para encubrir la manipulación, sino incluso para que ésta se convierta en una de sus señas de identidad ha sido el detonante que ha hecho saltar las alarmas" (Caminos et at., 2008). Y el resultado de esas alarmas que han saltado es la "permanente sospecha de que todas las imágenes que vemos están retocadas o manipuladas" (Felici, 2011: 222).

Los estudios publicados en Europa o en EE.UU. sobre la fotografía de prensa coinciden en considerar el alto valor comunicativo en la foto de la página impresa desde su función de señuelo para cazar al lector hasta la cognoscitiva para mejor comprender la "narración" de las noticias (Marauri Castillo, Rodríguez González y Cantalapiedra González 2011).

A pesar de los casos de manipulación fotográfica que se han dado los últimos años, según Caminos et al. (2008), los datos reales de manipulación fotográfica no son tan abundantes. En su opinión, los fotoperiodistas no tienen la intención de engañar al lector, más allá de los límites admitidos.

Ràfols (2011) opina por el contrario, que el desarrollo de la tecnología en el tratamiento y la manipulación de imágenes ha llegado a unos niveles que representan un instrumento potencial de pleno derecho para ser considerado en la elaboración de la información diaria audiovisual.

Pero la realidad es que se está cambiado el estatuto deontológico de la fotografía en su proceso digital. Los nuevos libros de estilo o nuevos códigos éticos y los despidos fulminantes de fotógrafos, son síntomas de una preocupación en el mundo informativo en general y la fotografía en particular.

\section{Fuentes y metodología}

En este artículo queremos abordar este tema desde una perspectiva analítica. Vamos a realizar un repaso breve de la historia corta pero intensa del fotoperiodismo de gue- 
rra desde sus inicios, desde la Guerra de Crimea (1854-1856), hasta los problemas que están encontrando los profesionales en Siria (2013). Demostraremos que algunas de las principales agencias de noticias han cambiado sus criterios, detallando las normas para reflejar así una nueva realidad.

Para hacer el estudio, hemos recurrido a los libros o manuales de estilo de las siguientes agencias:

a) Associated Press (AP): Fue la primera agencia norteamericana. Fundada en 1848 por cinco periódicos de Nueva York, en 1892, tras varias fusiones, se convertiría en la actual agencia Associated Press (Brajnovic, 1974). Entre sus hitos está el ser la primera en contar el asesinato de Abraham Lincoln, el ataque a Pearl Harbor o la muerte del papa Juan Pablo II (AP, 2013).

b) Thomson Reuters (Reuters): Nació en Londres en 1851, de la mano de Paul Julius Reuter, que comenzó utilizando palomas mensajeras para transmitir la información el primero (Thomson Reuters, 2014). Hoy, Thomson Reuters cuenta con 3.000 periodistas en su plantilla y su estrategia empresarial pasa por incrementar su presencia en redes sociales, aumentando la cobertura de los conflictos internacionales (Pereda, 2011).

c) Agencia France Press (AFP): Tiene sus orígenes en la agencia Havas, creada en 1835. Hasta 1944 no adquiere en nombre que tiene en la actualidad. Una de sus exclusivas mundiales fue dar la noticia de la muerte de Stalin el 5 de marzo de 1953. En 1985 se crea el servicio de fotografía internacional. En la actualidad cuenta con 500 fotógrafos que generan casi 3.000 fotografías al día (AFP, 2014)

d) European Pressphoto Agency (EPA): Fundada en 1985 por siete agencias de noticias europeas (ANP de Holanda, ANOP (ahora Lusa) de Portugal, ANSA de Italia, AFP de Francia, belga de Bélgica DPA de Alemania y EFE de España). Originalmente fue concebida como un vehículo para intercambiar fotografías entre las agencias miembros pero más tarde se fue expandiendo a nuevos mercados. A principios de 2003, se decidió ofertar su servicio de fotografía en todo el mundo. Trabajan 400 fotógrafos profesionales que generan una media de 1.300 fotografías al día (EPA, 2014).

e) La agencia EFE: Es la primera agencia de noticias en español y la cuarta del mundo. Este año 2014 cumple su 75 aniversario. Distribuye casi 3 millones de noticias al año en los diferentes soportes informativos: texto, fotografía, audio, video y multimedia, que llegan diariamente a más de dos millares de medios de comunicación en el mundo (Efe, 2014).

De estos manuales, hemos aislado los elementos que más nos interesaban y hemos comparado unos con otros. Y también hemos consultado libros de referencia en el ámbito de la fotografía y artículos de revistas científicas que nos han servido para contextualizar y enmarcar el debate generado en torno a la manipulación del fotoperiodismo de guerra. 


\section{Desarrollo}

\subsection{Guerra de Crimea}

La irrupción del fotoperiodismo de guerra tuvo lugar en la Guerra de Crimea, que se desarrolló de 1854 a 1856. El periódico The Times envió por primera vez a un corresponsal, Willian Howard Russell, que se encargó de cubrir el conflicto. Sus crónicas eran muy críticas con el gobierno británico y el ejército. Les hacía responsables numerosas muertes innecesarias causadas por su ineptitud y por no tener los medios necesarios para atender a los heridos. (Sontag, 2004).

El gobierno británico, viendo que la guerra se estaba volviendo impopular, decidó mandar a Roger Fenton y su ayudante, Marcus Sparling, a Crimea, durante cuatro meses, para publicar sus fotografías, en forma de grabados, en un periódico menos crítico, The Illustrated London News. La directriz era muy clara: proporcionar una impresión diferente, más benévola de lo que estaba ocurriendo. Para ello, Fenton buscó sus protagonistas, básicamente, según Pardo Despierto (1990), en los cuadros de oficiales y altos jefes, pero tampoco desdeñó el encuentro con la tropa.

Susan Sontag (2004) cuenta que Fenton, tenía instrucciones del Ministerio de Guerra de no fotografiar a los muertos, los mutilados y los enfermos. Debido a las limitaciones técnicas, sólo se ocupó de representar la guerra fotografiando a los oficiales británicos en escenas de descanso o a los soldados ocupándose del mantenimiento de las armas pero siempre bajo sus indicaciones.

Una de sus fotografías, que además es la icónica del conflicto, es "El valle de la sombra de la muerte", imagen que vemos en la Ilustración 2 a la derecha y que se realizó en un valle en las proximidades de Sebastopol. La imagen impacta por la cantidad de balas de cañón dispersadas por la carretera.

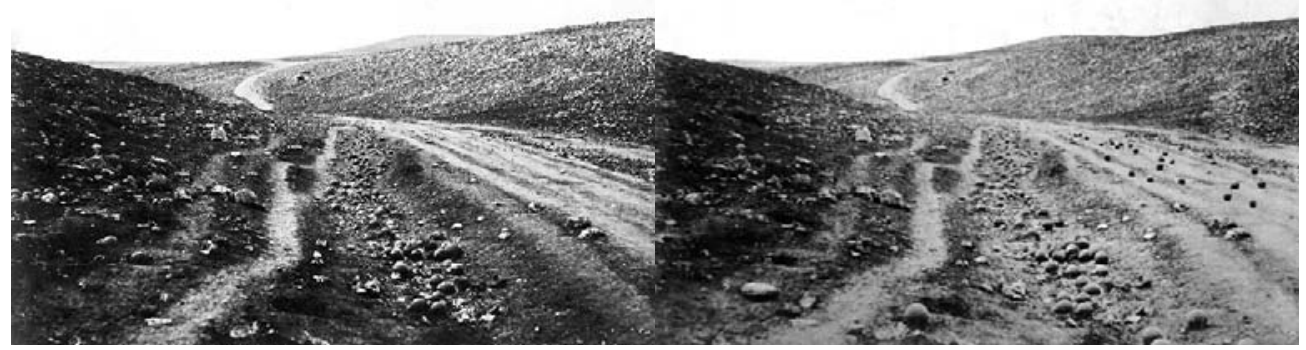

Ilustración 2: Primera exposición de Roger Fenton (izquierda) y

"El valle de la sombra de la muerte" (derecha)

Como podemos observar en la ilustración en la fotografía de la izquierda, Roger Fenton, realizó otra fotografía desde el mismo punto con el mismo encuadre, pero esta vez sin las balas de cañón dispersadas que tanto dramatismo le dan a la imagen. Muchos estudios revelan que la fotografía de la izquierda fue expuesta primera y que por tanto la segunda se habría manipulado.

\subsection{Guerra de Secesión (1861-1865)}

Según cuenta Rodríguez Porcel (2009), durante la guerra de Secesión norteamericana, docenas de profesionales fotografiaron la vida civil, las operaciones militares y los 
resultados en los campos de batalla. El procedimiento fotográfico más utilizado era el del colodión húmedo, que requería entre 5 y 20 segundos de exposición, por lo que no existen fotografías en combate, aunque sí podemos ver las primera imágenes de fallecidos en el frente.

En esa época, en nombre del realismo, se exigía, como explica Sontag (2004) mostrar hechos crudos y desagradables. La fotografía significaba componer, ya sea seres vivos posando o cadáveres. El deseo de arreglar los elementos de la foto no desapareció porque el tema estuviera inmóvil.

Marisol Romo Mellid (2006) recoge la historia de un cadáver que sirvió para dos fotografías y que perteneció, por caprichos de un fotógrafo, a los dos bandos enfrentados. En julio de 1863, Alexander Gardner y su asistente Timothy O'Sullivan fotografiaron a un soldado (del que, al parecer, insinuaban que era un federal), que había caído muerto sobre el pasto mientras subía una colina, fotografía que vemos en ilustración 3 a la izquierda.
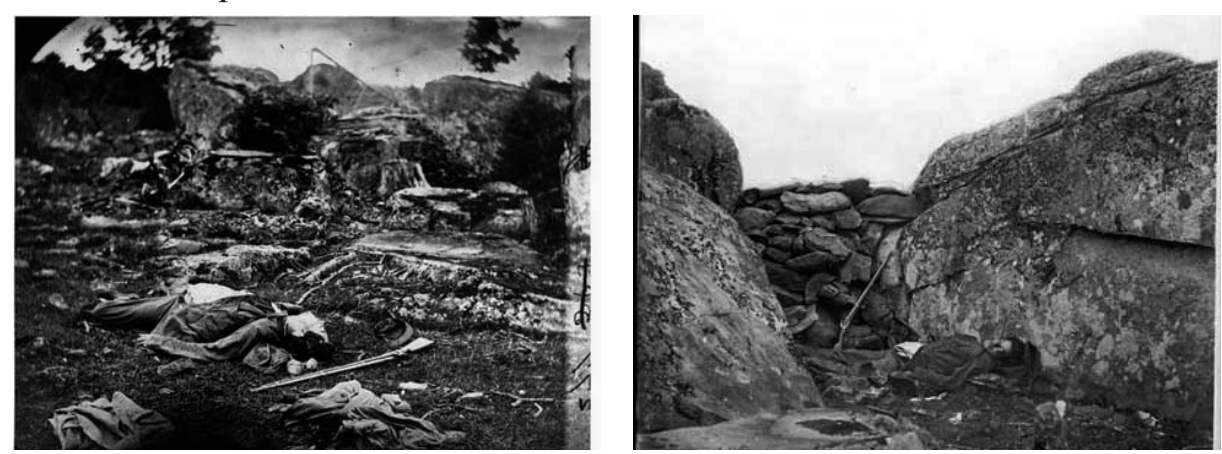

Ilustración 3: "El último sueño de un tirador" (izquierda) y

"El hogar de un tirador rebelde" (derecha) de A. Gardner

Al lado de donde encontraron el cadáver, estaba llamada "La Guarida del diablo", donde los francotiradores confederados habían construido una trinchera. Según Romo Mellid, como no encontraron cadáveres alrededor de este escenario, Gardner mandó que transportaran el cadáver anterior cuarenta metros arriba sobre una sábana para colocarlo en un fondo más fotogénico. Los fotógrafos luego dispusieron el rifle contra la pared y voltearon la cabeza del cadáver hacia la cámara, tomando la imagen de la derecha de la ilustración 3.

Romo (2006) afirma que se trata de una puesta en escena, en vez de una manipulación fotográfica, ya que "lo único que hicieron fue colocar a unos muertos que ya estaban allí. Es decir, la imagen no miente sobre el acontecimiento importante: la muerte de unos hombres en el campo de batalla". Otros investigadores como Burke (2005) consideran que por estos y otros muchos motivos las fotografías no son nunca testimonio de la historia.

\subsection{Primera Guerra Mundial}

Durante la Gran Guerra también se produjeron manipulaciones fotográficas, pero se solían hacer en el llamado cuarto oscuro, donde los fotógrafos revelaban sus pelícu- 
las y podían superponer varios negativos para crear una imagen más impactante de cara al espectador, como nos asegura Caballo Ardila (2005).

Uno de los precursores fue el australiano fotógrafo militar, Frank Hurley, con sus impactantes imágenes de los campos de batalla. La fotografía "An episode after the Battle of Zonnebeke" es un buen ejemplo. Hurley creó una imagen a partir de tres o cuatro negativos para mostrar la crueldad de la guerra. Los soldados pertenecen a un negativo, las bombas a otro y los aviones al tercero (Coslovich 2008).

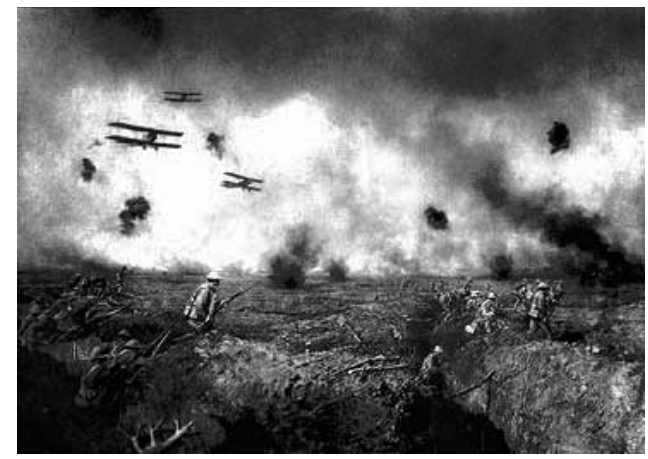

Ilustración 4: "An episode after the Battle of Zonnebeke" de Frank Hurley

\subsection{Segunda Guerra Mundial}

Son muchos los que consideran una reconstrucción el levantamiento de la bandera estadounidense en Iwo Jima el 23 de febrero de 1945, obra del fotógrafo de la Associated Press Joe Rosenthal. Sontag (2004) asegura que la ceremonia matutina del levantamiento de la bandera que siguió a la captura del Monte Suribachi, fue repetida aquel mismo día pero más tarde y con una bandera más grande que se transformaría en uno de los símbolos de la victoria estadounidense en esta guerra.

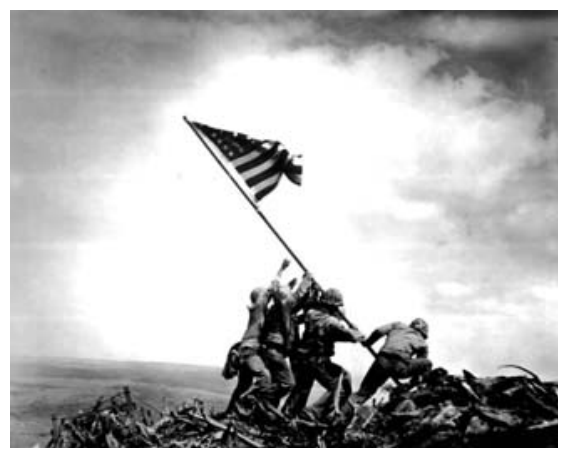

Ilustración 5: "Raising the Flag on Iwo Jima", de Joe Rosenthal

Parece ser que la primera vez que lo hicieron, los oficiales consideraron que la bandera era demasiado pequeña. Según la Agencia EFE, Rosenthal, dudó en ir a la cima cuando le dijeron que ya se había plantado la bandera estadounidense, pero finalmente fue y encontró que los soldados se preparaban para levantar una segunda 
bandera más grande. La toma no fue una pose, ya que los soldados estaban en lo suyo y Rosenthal aprovechó para tomar la imagen (Efe, 2006).

Otra imagen, también de la victoria y también icónica, es la del fotógrafo soviético Yevgeny Khaldei tomó de soldados rusos enarbolando la bandera roja sobre el Reichstag de Berlín el 2 de mayo de 1945.

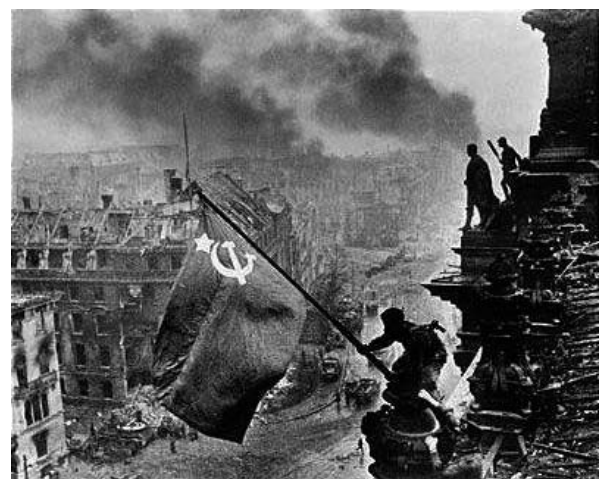

Ilustración 6: "Bandera soviética sobre el Reischstag", de Yevgeny Khaldei

La fotografía evidencia una gran destreza de los retocadores que transforman manteles en banderas y eliminan de la muñeca del soldado, rallando el negativo, un reloj posiblemente fruto del pillaje. Los máximos especialistas en este tipo de retoques pertenecieron a los países del Este, donde la eliminación de personajes considerados políticamente incorrectos ha sido una práctica habitual (Parejo Jiménez, 2008).

\section{Aparición de la fotografía digital}

A partir de la Guerra de Vietnam, los fotoperiodistas competían por primera vez con las televisiones, por lo que la exigencia de veracidad en las instantáneas que captaban era mucho mayor. A partir de esta guerra hay una certidumbre casi absoluta de que ninguna de las fotografías más conocidas son un truco y de que la práctica de inventar dramáticas fotos, de montarlas ante la cámara, parecía estar en vías de convertirse en un arte perdido.

Pero la verdadera revolución llegaría de la mano de la fotografía digital, que lo cambiaría todo: se acortan los tiempos de entrega de las fotografias, se multiplican las posibilidades de manipulación, además de forma más simple. Tras la captura, la imagen se descompone en píxeles sobre los que poder manipular, pudiendo incluirse otros elementos ajenos a la toma inicial o cambiar la iluminación.

La guerra de Afganistán (octubre 2001) y la invasión de Irak (marzo 2003), han sido las contiendas en las que se ha extendido el uso de la tecnología digital en la fotografía y que ha mostrado de nuevo, casos de manipulación en la fotografía de guerra.

\subsection{Brian Walski (2003)}

El 1 de abril de 2003 el periódico californiano Los Ángeles Times despidió a su fotógrafo Brian Walski, enviado al sur de Iraq para seguirla invasión aliada, por manipular una fotografía en la que combinaba dos imágenes de un soldado británico junto a 
un grupo de civiles a los que insta a refugiarse para protegerse de un ataque de las tropas iraquíes cerca de Basora (Caballo Ardila, 2005).
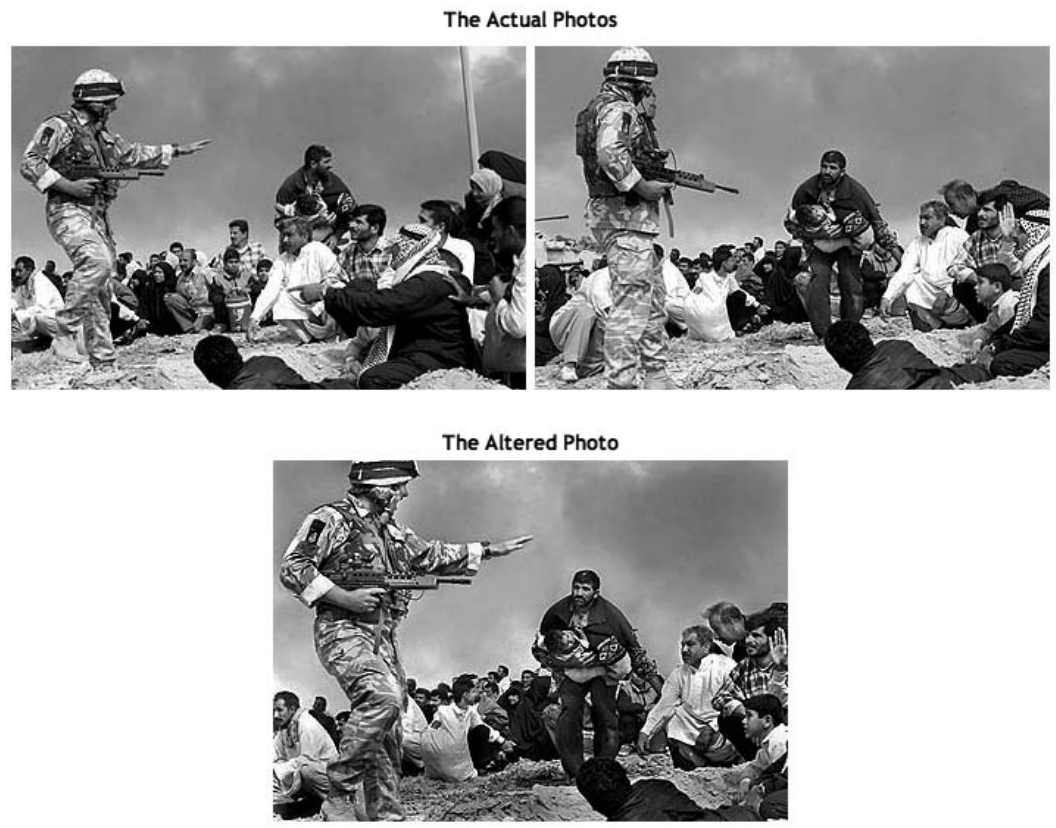

Ilustración 7: Fotografías de Brian Walski

Los editores del diario no se dieron cuenta de la manipulación hasta que no la vieron publicada: las personas que aparecían en el fondo de la fotografía estaban repetidas dos veces. Ese mismo día, por teléfono, el fotógrafo confirmó a su periódico que había mezclado dos imágenes, captadas con una diferencia de segundos, para obtener una imagen que tuviera más fuerza (Caminos et al., 2008).

El periódico además de despedir al fotógrafo que pertenecía a su plantilla desde 1998, tuvo que comunicar en su editorial que la fotografía que habían publicado el 31 de marzo en la portada, había sido manipulada, añadiendo que "las normas del 'Times' prohíben alterar el contenido de las fotografía" (Reuters, 2003).

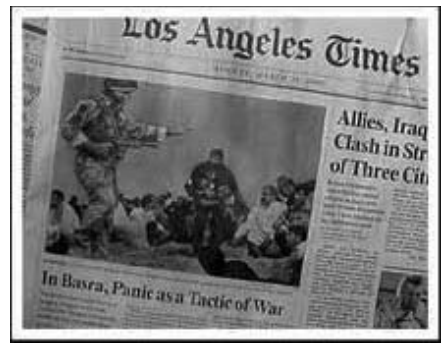

Ilustración 8: Portada de Los Ángeles Times 
El fotógrafo se mostró dolido con la decisión y se defendió declarando que cometió el error después de "un día extremadamente largo, caluroso y estresante" (Irby 2003).

Según Diego Caballo, redactor jefe del Servicio Gráfico de la agencia EFE, "este despido no lo podemos contemplar dentro de los daños colaterales de esta guerra despiadada ni tiene justificación alguna, aunque a veces se nos pasa por la cabeza que más de un reportero gráfico no sólo va al peligro de las guerras en precario de equipo de protección sino también de salario, y si quiere sobresalir de la miseria persigue imágenes que a veces no existen y se arriesga a saltar a la aventura por el precipicio de la manipulación" (2005: 63).

\subsection{Adnan Hajj (2007)}

Otro caso que acabó también con despido, fue el descubierto en agosto de 2007, por la agencia Reuters. La agencia de noticias terminó su relación con el fotógrafo libanés Adnan Hajj después de que éste manipulara una imagen de Beirut tras los ataques israelíes. El fotoperiodista simuló más humo en el cielo con el programa de edición gráfica Photoshop. La fotografía se publicó en la página web de la agencia, pero al día siguiente, tuvo que retirarla y reemplazarla por una no alterada, tras las críticas recibidas en muchos blogs, que señalaban que había sido manipulada. El fotógrafo se justificó afirmando que estaba tratando de remover marcas de polvo y que por culpa de las malas condiciones de iluminación había cometido un error, pero negó en todo momento el haber manipulado deliberadamente la instantánea.

Moira Whittle, jefa de relaciones públicas de Reuters, en un comunicado, anunció que esta manipulación representaba un grave incumplimiento de los estándares de la agencia y que por tanto no utilizarían más fotografías del fotógrafo colaborador (20minutos.es, 2007)

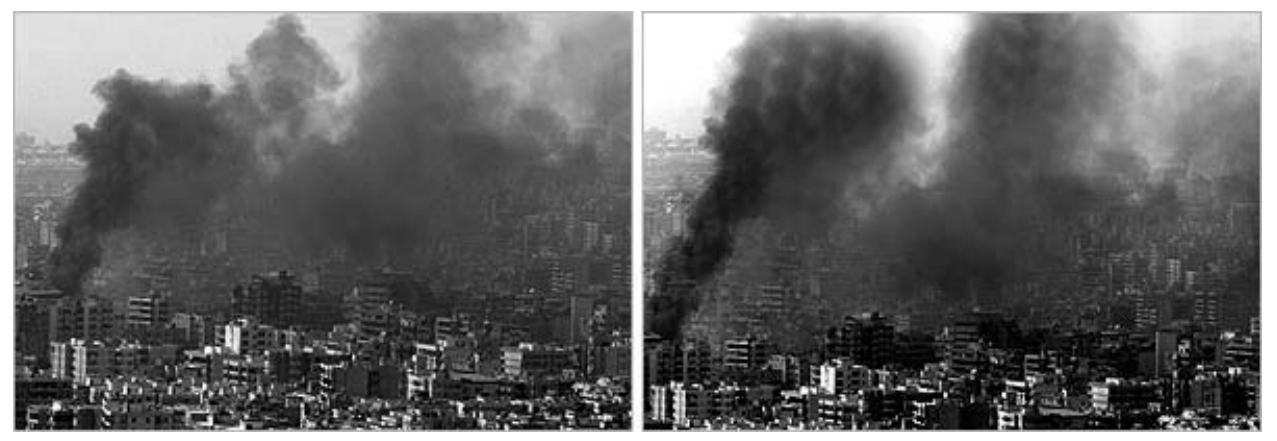

Ilustración 9: Fotografías (original y manipulada) de AdnanHajj

Reuters, tras retirar esta foto, revisó el resto de fotografías que tenían de Adnan Hajj y descubrió otra foto, fechada el 2 de agosto de 2006, que también había sido manipulada. En esta aparece un avión de combate israelí en el sur del Líbano, en el que se muestran tres bengalas, en lugar una, que es la que aparece en la imagen original (nbcnews.com, 2006) 


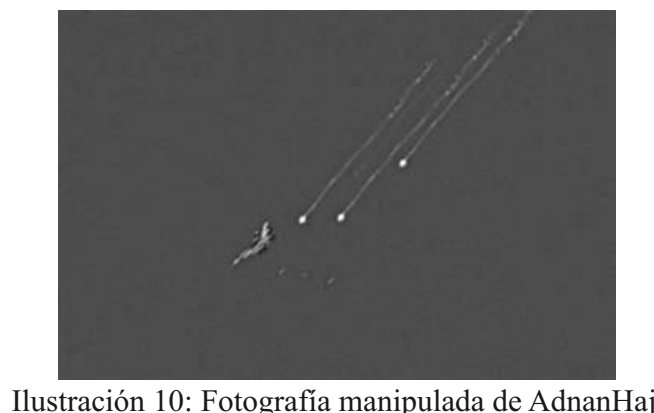

\subsection{France Press (2008)}

France Press distribuyó una fotografía sobre las pruebas de misiles de Irán que fue publicada en la portada de diferentes periódicos como Los Angeles Times, The Financial Times, The Chicago Tribune y en portales de internet como los de la BBC News, MSNBC, Yahoo! News, NYTimes.com. Esta foto estaba manipulada (Nizza \& Lyons, 2008).
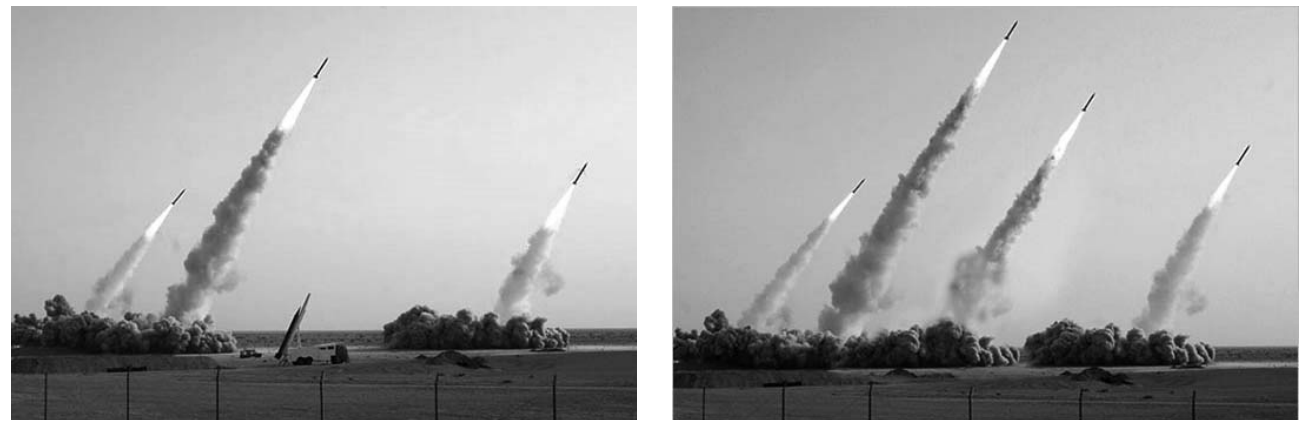

Ilustración 11: Fotografía (original y manipulada) distribuida por Reuters

El tercer misil que aparece en la segunda imagen de la ilustración 14 es en realidad la suma de otros dos de los que aparecen en la imagen. El humo es una réplica de los que aparecen bajo el cuarto proyectil, y el misil es una copia del segundo. La agencia francesa argumentó que la foto la cogieron de la página web Sepah News. Pero poco tiempo después había desaparecido y colgó la foto original, imagen que distribuiría Associated Press. Reuters aseguró que la imagen, al parecer, había sido modificada digitalmente por medios de comunicación iraníes estatales para así tapar el misil que podría haber fallado durante la prueba (elmundo.es, 2008).

\section{Análisis de los manuales de estilo}

Esta realidad ha obligado a las principales agencias de noticias del panorama internacional (Associated Press, Reuters, European Pressphoto Agency, France Press y EFE) a modificar y endurecer sus normativas respecto a la manipulación por parte de sus fotoperiodistas. 


\subsection{Reuters}

La agencia Reuters actualizó su Libro de Estilo en 2008, después del caso de su colaborador freelance Adnan Hajj, que ya hemos comentado más arriba. Ahora, dedican un apartado exclusivamente al programa de retoque, Photoshop. Afirman que, a pesar de ser un programa con muchas posibilidades, "usamos sólo una pequeña parte de su potencial capacidad para dar formato a nuestras imágenes, reportar y ajustar el tamaño de ellas y equilibrar el tono y el color". En este sentido, es la única agencia que deja claro la consecuencia de su mal uso: "alterar materialmente una imagen en Photoshop o cualquier otro software de edición de imágenes dará lugar al despido" (Reuters, 2008).

En el manual no sólo se detallan las reglas, sino que además se ofrece una guía de cómo operar, centrándose en la parte técnica y explican la política de Reuters sobre alguna de las herramientas del programa. Al final del capítulo, enumera lo que está permitido y lo que no. Básicamente lo que se le permite al fotógrafo es recortar la imagen que envía, ajustar niveles y fijar la resolución. Luego en redacción se termina el retoque, donde sí se permiten otros ajustes, pero siempre siguiendo las reglas marcadas.

\subsection{EFE}

Más actual es el Libro de estilo urgente, que publicó la agencia EFE en septiembre de 2011. En este manual, recopila las regulaciones de los géneros informativos de la agencia y los distintos criterios éticos inspirados en el Estatuto de la Redacción aprobado en el 2006.

En el libro de EFE, deja claro cuál es la máxima a respetar: "A la hora de editar las fotografías rigen las mismas normas que cuando se toman: la objetividad es la primera obligación del periodista y en ningún caso se debe manipular o realzar la realidad mediante las herramientas disponibles en el ordenador" (Agencia EFE, 2011).

Por ello, sólo permite que las fotos se procesen lo estrictamente necesario, utilizando al mínimo todas las posibilidades que permiten los programas de retoque. Pero, en contra del criterio de otras agencias, sí permite algunos procedimientos, como "ampliar para excluir distracciones, como personas u objetos irrelevantes" o "disimular reflejos y equilibrar las luces altas y las sombras, pero sin realce artificial" (Agencia EFE, 2011).

A la hora de establecer las técnicas no autorizadas, hace hincapié en la prohibición de hacer retoques selectivos, enmascaramientos, difuminados o clonar áreas, así como realzar la nitidez de forma selectiva en alguna zona.

También establece que todo redactor gráfico tiene que entregar siempre los originales de la cobertura, en formato RAW, que es el archivo original. Es decir, lo más parecido al negativo de la fotografía analógica, donde se recoge toda la información almacenada por el sensor de la cámara. El archivo RAW sirve para confirmar que la posición de cada píxel está exactamente en el mismo lugar que en el archivo JPEG (la imagen entregada por el fotógrafo) para descartar cualquier posibilidad de que se trate de una imagen compuesta. 


\subsection{Associated Press}

La agencia Associated Press tiene colgado en su web su Estatuto de Valores y principios. En esta normativa específica, dedica un apartado a las imágenes fotográficas. Su declaración de intenciones está clara desde el principio: "Las imágenes de AP siempre deben decir la verdad. No alterar o manipular el contenido digital de una fotografía de cualquier manera".

Eso sí, a la hora de retocar las imágenes, acepta el uso de la herramienta de clonación para eliminar el polvo en los sensores de la cámara y arañazos en los negativos escaneados o copias escaneadas. (AP, 2013)

Santiago Lyon, vicepresidente y director de fotografía de Associated Press asegura que durante los últimos años, la agencia ha invertido en un programa de formación diseñado para asesorar y aclarar sus dudas sobre la práctica del Photoshop a sus más de 350 fotógrafos y editores. Además, han trabajado con Hany Farid, un experto en fotografía forense de la Universidad de Dartmouth, que ha desarrollado un programa que es capaz de detectar la manipulación fotográfica, aunque, como dice Lyon, para verificar una alteración se necesita tiempo y la tecnología todavía muy reciente y muchas veces no es capaz de detectarlo. (Lyon, 2012)

\subsection{France Press}

France Press ha realizado ya nueve ediciones de su "Manual de Estilo". Su objetivo ha sido siempre adaptarse a las nuevas realidades que imponen las nuevas tecnologías, como las redes sociales y, por supuesto, la existencia de imágenes en estas redes sociales. Al igual que el resto de agencias, en su Manual establece que sus fotografías sólo "reflejan estrictamente la realidad. Nada se suma o resta a la imagen, incluso cuando no es técnicamente perfecto". Y deja claro que sus fotografías no permiten ningún tipo de manipulación, escenográfica o técnica, aunque el fin sea hacer más estética.

La máxima es no distorsionar el significado de la imagen o su valor informativo. Por ello, no permite que los objetos de una foto se puedan mover, añadir, eliminar o modificar. Sí que permite el difuminado para respetar el anonimato de las personas o por un imperativo legal. Otra prohibición es la distribución de primeros planos de las lesiones o las extremidades y cuerpos desgarrados, pero aplicándose de forma diferente según el continente. Por ejemplo, en Asia se publican este tipo de imágenes con más facilidad. Y recomienda evitar los encuadres que pueden distorsionar la realidad como plano cerrado de un grupo que puede hacer creer que es más numeroso del real.

\subsection{European Pressphoto Agency}

Los fotógrafos de la EPA se rigen por el código de ética de la americana Asociación Nacional de Fotoperiodistas (NPPA) cuya máxima es "captar el momento de una manera honesta y completa". Por eso, su código les conmina a resistirse a ser manipulados por oportunidades fotográficas orquestadas y les anima a dar contexto cuando estén fotografiando o grabando a los sujetos, evitando estereotipos.

Asimismo, durante el ejercicio de su profesión, les pide no contribuir, alterar, o influenciar en los eventos intencionalmente. También hace referencia a la edición fotográfica. Se exige "mantener la integridad del contenido y contexto de la imagen. No se 
deben manipular las imágenes ni añadir o alterar el sonido de ninguna forma que pueda confundir al público o representar los sujetos de una forma incorrecta" (NPPA, 2012).

Ahora veremos en el cuadro algunas de las características comunes:

\begin{tabular}{|c|c|c|c|c|c|}
\hline ANÁLISIS MANUALES DE ESTILO & AP & REUTERS & AFP & EPA & EFE \\
\hline Recortar la imagen & SI & SI & & & SI \\
\hline Mínima corrección de color/tono & SI & SI & & & SI \\
\hline $\begin{array}{l}\text { Sutil uso de la herramienta } \\
\text { subexponer/sobreexponer }\end{array}$ & SI & SI & & & SI \\
\hline $\begin{array}{l}\text { Cuentagotas para comprobar/Ajustar } \\
\text { los grises }\end{array}$ & SI & SI & & & \\
\hline $\begin{array}{l}\text { Eliminar los punto de polvo/agua } \\
\text { derivados del objeto o del sensor }\end{array}$ & & & & & SI \\
\hline $\begin{array}{l}\text { Añadir, modificar o eliminar } \\
\text { elementos en la imagen }\end{array}$ & NO & NO & NO & NO & NO \\
\hline $\begin{array}{l}\text { Modificar fondos (difuminarlo o } \\
\text { eliminarlos) }\end{array}$ & NO & & & & NO \\
\hline Exceso corrección de color & NO & NO & & & NO \\
\hline Configuración de la cámara & & $\begin{array}{l}\text { La saturación debe } \\
\text { estar en "estándar" } \\
\text { o en OFF }\end{array}$ & & & $\begin{array}{l}\text { Prohibido usar las } \\
\text { herramientas para } \\
\text { hacer cambios no } \\
\text { autorizados }\end{array}$ \\
\hline Difuminar/oscurecer las caras & $\begin{array}{c}\text { NO (salvo ser } \\
\text { aprobado por un } \\
\text { editor) }\end{array}$ & & $\begin{array}{c}\mathrm{Si}, \text { para } \\
\text { mantener el } \\
\text { anonimato }\end{array}$ & & $\begin{array}{l}\text { Si, según normativa } \\
\text { (fuerzas de seguridad, } \\
\text { menores o víctimas) }\end{array}$ \\
\hline
\end{tabular}

Como vemos en el cuadro, todas las agencias permiten realizar cambios que no afecten a la imagen fotografiada, es decir, permiten técnicas que también podrían realizarse en un cuarto oscuro, como recortarla y ajustar su iluminación, sobreexponiendo o subexponiendo la imagen.

Algo en lo que están todas de acuerdo es en la prohibición de modificar la imagen, ya sea añadiendo o eliminando elementos que aparecen en la fotografía original. La fotografía tiene que ser lo más cercana posible a la realidad. Esta norma ha sido la principal causante de los últimos despidos de los fotoperiodistas de guerra, ya que algunos utilizaron la herramienta para componer una fotografía partiendo de dos imágenes, y eliminaron o añadieron elementos para conseguir mayor dramatismo.

Reuters, además, no permite iluminar, oscurecer o difuminar la imagen excesivamente porque considera que engañaría al espectador. Se disfrazarían ciertos elementos de la imagen y eso modificaría sus condiciones originales. Agencias como EFE o Reuters permiten ocultar las caras por seguridad o para mantener el anonimato, mientras que AP sólo lo permite con la autorización del editor.

\section{Incongruencia informativa}

Hay ocasiones en las que son los propios medios los que manipulan esas fotografías sin que parezca haber un criterio común. Normalmente, se trata de fotografías que tienen un componente sangriento, que pueden ser demasiado agresivas para un determinado tipo de público. Este debate se ha desarrollado sobre todo en foros anglosajones, donde la reproducción de imágenes sangrientas plantea más dudas: una de las normas, al menos para los llamados 'family papers', es saber sintonizar con la 
audiencia, conociendo los niveles de tensión que los lectores están dispuestos a soportar.

En el caso del 11-S, por ejemplo, la mayoría de los diarios estadounidenses evitaron las escenas más duras, al menos en las portadas, como las de las personas lanzándose por las ventanas de las Torres Gemelas de Nueva York (Castaños, 2004).

También los atentados del 11 de marzo de 2004 en Madrid, fueron un escenario propicio para que algunos medios manipularan las fotografías con el objetivo claro de no reproducir imágenes demasiado escabrosas. Una foto de Pablo Torres Guerrero, que reprodujo en su portada El País y que distribuyó a todo el mundo la agencia Reuters, suscitó la polémica. Muchos diarios la utilizaron para ilustrar la tragedia aunque un "detalle" hizo que debiese ser editada: junto a la vía del tren, además de heridos y equipos de emergencia, aparecía el trozo de una ensangrentada.

Como ha señalado acertadamente Juan Varela (2004) algunos medios en Estados Unidos y Gran Bretaña optaron por maquillar el impacto y de ahí el debate sobre la publicación de determinadas imágenes y su manipulación (Castaños, 2004).

La prensa británica como The Times suprimió el trozo de pierna poniendo en su lugar más gravilla usada en las vías del tren. El Daily Telegraph, y el belga Gazet van Antwerpen también optaron por hacerlo desaparecer. Por el contrario, el canadiense Toronto Star y el inglés The Guardian, rebajaron los colores de la pierna amputada para restarle dureza (Caballo Ardilla, 2005: 66).

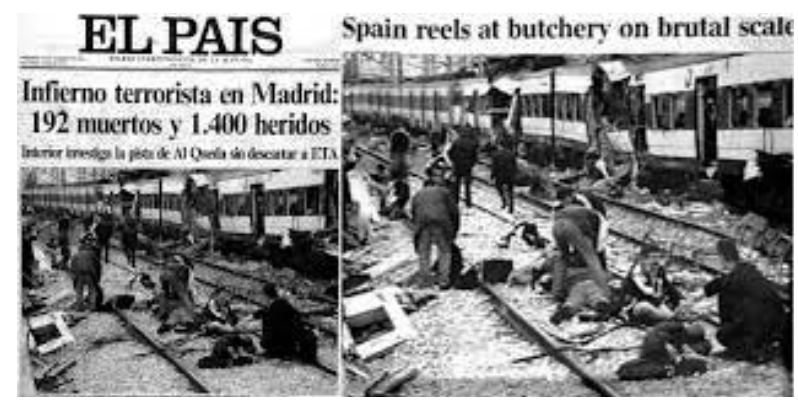

Ilustración 12: Portada de El País del 12 de marzo y portada manipulada de un medio inglés

Aunque en los medios españoles es habitual la aparición de fotografías de fuerte contenido, en el caso de las portadas del 12 de marzo, la mayoría de los diarios optaron por mostrar escenas de alguno de los trenes pero menos del cuarenta por ciento muestran heridos, cadáveres o restos humanos (Castaños, 2004).

En los atentados que se produjeron durante el maratón de Boston en abril del 2013, el periódico el Daily News, decidió hacer desaparecer las heridas en la pierna de uno de los heridos. El periódico se negó a hacer declaraciones sobre su decisión editorial a pesar de las críticas de algunos lectores (Beaujon, 2013).

Si el objetivo es artístico nadie va a sentirse escandalizado. Si el objetivo es censurar o "proteger" al lector, quizás esta manipulación fotográfica no deba ser interpretada sino como una variante más de las muchas posibilidades de manipulación que los medios utilizan constantemente (Caminos et al., 2008). 


\section{Conclusiones}

La manipulación fotográfica se ha convertido en un riesgo para las empresas periodísticas, que no aceptan que el fotoperiodista adultere la imagen más allá de unos simples retoques estéticos.

Esta manipulación en el fotoperiodismo de guerra ha desembocado en el despido fulminante de fotógrafos y colaboradores en agencias de noticias de importancia internacional.

La Guerra de Vietnam marca un antes y un después en el fotoperiodismo de guerra, gracias a la aparición de las televisiones. Los lectores comienzan a desconfiar de las manipulaciones y rechazan cualquier tipo de intervención externa del fotógrafo en la imagen.

La generalización del uso de la fotografía digital a partir de las guerras de Afganistán (2001) y la invasión de Irak (2003), ha vuelto a poner en evidencia el problema de la manipulación deliberada de las imágenes gracias al uso de programas informáticos que facilitan esa adulteración de la instantánea.

Todas las agencias estudiadas (Associated Press, Reuters, Reuters, Reuters y EFE), permiten a sus fotógrafos, según aseguran en sus normativas internas, recortar y ajustar la iluminación de las fotografías.

En lo que coinciden las cinco agencias de noticias cuyos manuales hemos estudiado, es en prohibir la modificación de la fotografía original, que tiene que ser lo más cercana posible a la realidad.

A pesar de la dureza de las normas de las agencias de noticias respecto a sus propios fotógrafos, en ocasiones han sido los medios de comunicación los que han modificado unilateralmente las imágenes, para evitar a los lectores fotos demasiado escabrosas o que incluyeran elementos que pudieran herir la sensibilidad del lector.

Sería conveniente que tanto agencias de noticias como medios de comunicación en general, suscribieran un manifiesto o código ético de obligado cumplimiento, para garantizar la veracidad de las imágenes que utilizan y cerciorarse de la procedencia de las instantáneas.

Está claro que, después de décadas de manipulaciones más o menos burdas, las agencias no han regulado esta cuestión hasta que les ha afectado en la credibilidad y se han visto en la tesitura de despedir fotógrafos por manipular instantáneas.

La regulación redunda en una seguridad para el fotógrafo (sabe dónde está el límite, y dónde se arriesga a ser despedido), para la agencia (sabe que sus fotógrafos saben dónde está el límite y por tanto reduce la arbitrariedad a la hora de despedir a alguien), y para el medio abonado, que sabe que esa imagen que recibe de agencia reúne determinadas condiciones. En último término, también es seguridad para el lector.

Es fundamental que los medios tomen conciencia de que la distribución de imágenes manipuladas es un peligro que supone un daño en la credibilidad de los medios ante los ciudadanos y acrecienta la falta de confianza de los receptores de esas imágenes en los medios que las difunden. 


\section{Referencias bibliográficas}

20MINUTOS.ES (7 de agosto de 2007): "Despedido de Reuters por manipular una foto de Beirut". http://www.20minutos.es/noticia/146529/0/beirut/foto/manipulada/ [Consulta: 15/01/2014]

AGENCIA EFE (2011): Libro del estilo urgente. Madrid, Galaxia Gutenberg.

AFP (2014): “L'AFP en números”. http://www.afp.com/es/agencia/afp-en-numeros/ [Consulta: 01/02/2014]

ALBARRÁN, Juan (2010): "Mise en scène: fotografía y escenificación”. Discursos fotográficos, 193-209.

ASSOCIATED PRESS (2013): “AP News Values \& Principles” http://www.ap.org /company/news-values [Consulta: 13/01/2014]

ASSOCIATED PRESS (2013): “AP'S History”. http://www.ap.org/company/history/ap-history [Consulta: 15/01/2014]

ASSOCIATED PRESS (23 de enero de 2014): "Echan a un ganador del Pulitzer por trucar una foto de la guerra de Siria". www.clarin.com: http://www.clarin.com /mundo/Echan-ganador-Pulitzer-guerra-Siria_0_1071493157.html [Consulta: 24/01/2014]

BEAUJON, Andrew (17 de abril de 2013): “Daily News won't comment on why it altered photo from Boston explosions". http://www.poynter.org/latest-news/mediawire/210601/daily-news-wont-comment-on-why-it-altered-photo-from-boston-exp losions/ [Consulta: 01/02/2014]

BRAJNOVIC, Luka (1974): Tecnología de la información. Pamplona, Universidad de Navarra.

BURKE, Peter (2005): Visto y no visto. Barcelona, Crítica.

CABALLO ARDILA, Diego (2005): "Imágenes para engañar a la historia". Cuadernos de periodistas, 55-68.

CAMINOS MARCET, José María; MARÍN MURILLO, María Flora; y ARMENTIA VIZUETE, José Ignacio (2008): "La fotografía digital, nuevos retos e interrogantes: reflexiones en torno a la credibilidad y al concepto de autor en el fotoperiodismo actual". Telos: Cuadernos de comunicación e innovación, 49-65.

CASTAÑOS, Ángel J. (2004): "Diseño para acontecimientos excepcionales: los diarios españoles ante los atentados del 11 de marzo". Estudios sobre el Mensaje Periodístico, Vol 10, pp. 67-84. Madrid, Servicio de Publicaciones de la Universidad Complutense. Disponible en: http://revistas.ucm.es/index.php/ESMP/article /view/ESMP0404110067A

COSLOVICH, Gabriella (28 de noviembre de 2008): "Picture reveals trench horrors". http://www.theage.com.au/national/picture-reveals-trench-horrors-200811115mkd.html [Consulta: 01/02/2014] 
EFE (22 de agosto de 2006): "Joe Rosenthal, célebre fotógrafo". http://www.elmundo.es/elmundo/2006/08/21/obituarios/1156167053.html [Consulta: 27/01/2014]

EFE (2014): "Presentación". http://www.efe.com/efe/queesefe/presentacion/usa/5 [Consulta: 02/02/2014]

ELMUNDO.ES (11 de julio de 2008): "Los misiles iraníes se multiplican por obra y gracia de Photoshop". http://www.elmundo.es/elmundo/2008/07/10/comunicacion/1215708785.html [Consulta: 01/02/2014]

EPA (2014): "Epa Company Culture”. http://www.epa.eu/about-epa/company-culture [Consulta: 01/02/2014]

EPA (2014): "Epa History”. http://www.epa.eu/about-epa/history [Consulta: 01/02/2014]

FORMIGUERA, Pere (2006): "Una fotografía tan hermosa que parece una fotografía". Exit: imagen y cultura, 51.

IRBY, Kenneth (2 de abril de 2003): "L.A. Times Photographer Fired Over Altered Image". www.poynter.org: http://www.poynter.org/how-tos/newsgathering-storyte1ling/9289/1-a-times-photographer-fired-over-altered-image/ [Consulta: 16/01/2014]

LYON, Santiago (2012): "Detecting the Truth in Photos". Nieman Reports, 7-9.

MARAURI CASTILLO, Íñigo; RODRÍGUEZ GONZÁLEZ, María del Mar; y CANTALAPIEDRA GONZÁLEZ, María José (2011): "La ilustración del dolor: cobertura fotográfica de los sucesos en los diarios deinformación general en España (1977-2000)". Estudios sobre el Mensaje Periodístico, pp. 513-529. Madrid, Servicio de Publicaciones de la Universidad Complutense. [http://dx.doi.org/10.5209 /rev_ESMP.2011.v17.n2.38128]

MARZAL FELICI, Javier (2011): "Pensar la fotografía en la era digital". adComunica: revista científica de estrategias, tendencias e innovación en comunicación, pp. 221-225.

NBCNEWS.COM (7 de agosto de 2006): "Altered images prompt photographer's firyng”. http://www.nbcnews.com: http://www.nbcnews.com/id/13165165 /\#.UuvZPft5at8 [Consulta: 16/01/2012]

NIZZA, Mike \& LYONS, Patrick J. (10 de julio de 2008): "In an Iranian Image, a Missile Too Many". http://thelede.blogs.nytimes.com: http://thelede.blogs.nytimes.com/2008/07/10/in-an-iranian-image-a-missile-too-many/ [Consulta: 19/01/2014]

NPPA (2012): "NPPA Código de ética”. https://nppa.org/page/631 [Consulta: $16 / 01 / 2014]$

PARDO DESPIERTO, Juan (1990): "La fotografía y lo militar, su filosofía y su estética". Historia del arte, pp. 307-332.

PAREJO JIMÉNEZ, Nekane (2008): "De la fotografía documental al documento digital". ZER, pp. 179-196. 
PEREDA, Cristina (2 de noviembre de 2011): "Reuters quiere ser más que una agencia". http://blogs.elpais.com/periodismo-con-futuro/2011/11/reuters-quiere-sermas-que-una-agencia.html [Consulta: 15/02/2014]

RÀFOLS CABRISSES, Rafael (2011): "Infografía audiovisual: de la imagen al espacio". Estudios sobre el Mensaje Periodístico, vol. 17, núm. 2 (julio-diciembre), pp. 569-579. Madrid, Servicio de Publicaciones de la Universidad Complutense.

REUTERS (3 de abril de 2003): "Los Angeles Times despide a un fotógrafo por manipular una imagen para añadirle dramatismo". http://www.elmundo.es/elmundo/2003/04/02/enespecial/1049305403.html [Consulta: 13/01/2014]

REUTERS (6 de octubre de 2008): "A Brief Guide to Standards, Photoshop and Captions". http://handbook.reuters.com: http://handbook.reuters.com/index.php?title =A_Brief_Guide_to_Standards\%2C_Photoshop_and_Captions [Consulta: $29 / \overline{0} 1 / 201 \overline{4}]$

REUTERS (2013): www.thomsonreuters.com. www.thomsonreuters.com/about/company_history/?view=Standard=1890_1790 [Consulta: 03/03/2013]

RODRÍGUEZ PORCEL, Marco Antonio (2009): "La fotografía durante la Guerra de Secesión (1861-1865)". Clío. History and History Teaching. Clio 35, 2009 (Proyecto CLIO, REDIRIS) http://clio.rediris.es ISSN 1139-6237

ROMO MELLID, Marisol (20 de 7 de 2006): "Horror y propaganda: fotografías de guerra". http://www.solromo.com/fotografia/53-horror-y-propaganda-fotografiasde-guerra-i [Consulta: 28/01/2014]

SONTAG, Susan (2004): Ante el dolor de los demás. Madrid, Santillana Ediciones Generales.

THOMSON REUTERS (2014): “Company History". http://thomsonreuters.com /about-us/company-history/ [Consulta: 13/02/2014]

VARELA, Juan (31 de marzo de 2004): "El dolor y la verdad de la imagen". http://www.periodistas21.com/2004_03_01_archive.html [Consulta: 13/02/2014] 